\title{
Resveratrol; an inflammasome inhibitor and a potential therapy for severe cases of COVID-19
}

\author{
Mohammad-Reza Mahmoudian-Sani ${ }^{\circledR}$, Ali Saeedi Boroujeni' ${ }^{2,3}{ }^{\circledR}$, Ali Khodadadi ${ }^{\circledR}$, Sheyda Houshmandfar ${ }^{\circledR}$, \\ Sima Tahmaseby Gandomkari ${ }^{10}$, Arash Alghasi ${ }^{1 *}{ }^{\circledR(}$ \\ 'Thalassemia and Hemoglobinopathy Research Center, Health Research Institute, Ahvaz Jundishapur University of Medical \\ Sciences, Ahvaz, Iran \\ ${ }^{2}$ Department of Immunology, Faculty of Medicine, Ahvaz Jundishapur University of Medical Sciences, Ahvaz, Iran \\ ${ }^{3}$ Immunology Today, Universal Scientific Education and Research Network (USERN), Tehran, Iran
}

\section{*Correspondence to Arash Alghasi, Email: arashalqasi@yahoo.com, alghasi-a@ajums.ac.ir}

Received 26 Apr. 2021 Accepted 23 June 2021 Published online 6 July 2021

Keywords: Resveratrol COVID-19, Inflammasome, Therapy, Pandemic, Reactive oxygen species, SARS-CoV-2

\begin{abstract}
Severe acute respiratory syndrome coronavirus 2 (SARS-CoV-2) has infected more than 126 million people worldwide and deaths exceed two million. Virological features of SARS-CoV-2, including its genomic sequence, have been identified but the mechanisms governing coronavirus disease 2019 (COVID-19) immunopathogenesis have remained uncertain. Severe COVID-19 is associated with a cytokine storm, chronic inflammation, neutrophilia, lymphocyte dysfunction, lymphopenia, reduction in T-lymphocytes and natural killer (NK) cells, disruption in viral clearance, and neutrophil/macrophage infiltration in the lungs. In many cases, patients develop acute lung injury (ALI), acute respiratory distress syndrome (ARDS), and/or multiple-organ dysfunction syndrome (MODS). Resveratrol reduces the expression of inflammasome activators such as thioredoxin-interacting protein (TXNIP) and nuclear factor erythroid $2(\mathrm{NrF} 2)$ and increases that of the inflammasome inhibitor, i.e., NAD-dependent deacetylase sirtuin-1 (SIRT1). Resveratrol is able to inhibit the production of reactive oxygen species (ROS) and the activation of inducible nitric oxide synthases (iNOS). It affects signaling pathways including mitogen-activated protein kinase (MAPK) and nuclear factor kappa $\mathrm{B}(\mathrm{NF}-\mathrm{KB})$ thereby further inhibiting inflammasomes. Because of its anti-inflammasome, anti-inflammatory, and anti-oxidant effects and considering the key role of inflammation and cytokine storm in disease severity and poor patient outcomes, it is concluded that resveratrol can be useful in the treatment of COVID-19. Given the persistence of the COVID-19 pandemic and the challenges of extensive vaccination in all countries, it is important to achieve more effective treatments to decrease the mortality rate and severity of severe injuries following COVID-19. Given all the effects reviewed in this article, resveratrol at a dose of up to $600 \mathrm{mg}$ per day can be exploited as a potential adjunctive therapy for COVID-19 patients.
\end{abstract}

\section{Introduction}

Severe acute respiratory syndrome coronavirus 2 (SARS-CoV-2) belongs to the family of betacoronaviruses, which induce acute respiratory syndrome (SARS) in the lower respiratory tract. Severe inflammation is a leading cause of mortality. The occurrence of a phenomenon called cytokine storm, along with acute respiratory distress syndrome (ARDS) and acute lung injury (ALI), are the main pathological complications in COVID-19 patients (1). Inflammasomes are molecular platforms, activated by infection or stress, to trigger the maturation of pro-inflammatory cytokines to engage innate immune defenses. Recently developed therapeutics target inflammasome activity in inflammatory diseases but the role of inflammasomes in the current COVID-19 crisis is ill-defined and the potential use of anti-inflammasome agents is not being avidly pursued. Structural models

\begin{abstract}
Key point
Our review study showed, resveratrol at a dose of up to $600 \mathrm{mg}$ per day might be exploited as a potential adjunctive therapy for COVID-19 patients.
\end{abstract}

of mature peptides of SARS-CoV-2 show that the pathogen contains all the inflammasomeactivating proteins (2). Resveratrol, a member of the family of polyphenols, called viniferine, is found in plants such as eucalyptus, iris, blackberries, peanuts, and grapes (3). Resveratrol is an antioxidant proven to be beneficial in some diseases (4). This review summarizes the diverse effects of resveratrol with a focus on inhibition of inflammasomes and suppression of inflammation under a variety of pathological conditions.

Anti-inflammatory effect of resveratrol Resveratrol is able to inhibit cyclooxygenases,

\footnotetext{
Copyright $(\odot 2022$ The Author(s); Published by Nickan Research Institute. This is an open-access article distributed under the terms of the Creative Commons Attribution License (http://creativecommons.org/licenses/by/4.0), which permits unrestricted use, distribution, and reproduction in any medium, provided the original work is properly cited.
} 
which also prevents the production of pro-inflammatory molecules by macrophages and inhibiting the expression of pro-inflammatory cytokines such as interleukin 6 (IL-6) and C-reactive protein (CRP). Moreover, resveratrol might also neutralize the formation of secondary inflammatory products such as reactive oxygen species (ROS) and other oxidative ones in a host (5). Besides, it was shown that resveratrol causes inducible nitric oxide synthases (iNOS) expression; thereby, it can be said that it has antihypertensive effects. This compound can further inhibit NF- $\mathrm{kB}$ by reducing $\mathrm{H}_{2} \mathrm{O}_{2}$ production, as well as inhibiting IkB kinase (IKK) and inhibiting phosphorylation or deacetylation of transcription factor p65 (6). However, some previous studies have suggested that the role of resveratrol might be mediated by other metabolic pathways including the stimulatory effect of resveratrol on adiponectin secretion (7). Adiponectin and leptin are among the hormones that have been confirmed to play significant roles in exacerbating metabolic inflammation. In addition, resveratrol can prevent obesity through the inhibition of the increased central leptin resistance. However, one of the salient features of resveratrol is its inhibitory role in inflammasomes.

Effect of resveratrol on inflammasome in lung diseases Resveratrol has several anti-inflammatory properties in many lung diseases (8). As reported earlier, nickel is a common environmental pollutant that can disrupt the lungs. Furthermore, this chemical element can increase the expression of inflammatory cytokines including IL$1 \beta$, TNF- $\alpha$, IL-6, and IL-8. In addition, it was shown to activate p38 mitogen-activated protein kinase (MAPK), NF- $\mathrm{kB}$, and NLR family pyrin domain containing 3 (NLRP3), while resveratrol can reverse these effects (9). Correspondingly, the inhalation of suspended fine particulate matter (PM2.5) can cause pneumonia and fibrosis. Besides, PM2.5 exposure activates autophagy and NLRP3 inflammasome in lungs. Therefore, the treatment with resveratrol can inhibit the PM-induced pneumonia and fibrosis, suppress autophagy, and activate NLRP3 inflammasome (10). Additionally, resveratrol reduces the prevalence of pneumonia caused by Staphylococcus aureus by inhibiting NLRP3 inflammasome. It can significantly minimize mortality resulted from $S$. aureus in rats as well as the lower levels of cytokines in rats infected by $S$. aureus (11). Accordingly, resveratrol therapy can moderate the pathological damage of lungs and pulmonary edema, as well as moderating neutrophil infiltration caused by lipopolysaccharides (LPS). Furthermore, resveratrol reverses the increased IL- $1 \beta$ and IL-18 caused by LPS in bronchoalveolar lavage fluids. Therefore, its injection not only suppresses NF-kB (p65) nuclear translocation, NF-kB activity, and ROS production in the LPS-exposed rats, but it also inhibits thioredoxin-interacting protein (TXNIP) expression and TXNIP-NLRP3 interaction in the lung tissues. At the same time, resveratrol augments
NAD-dependent deacetylase sirtuin-1 (SIRT1) in LPSexposed rats (12).

The effect of resveratrol on inflammasome in cardiovascular diseases

Resveratrol downgrades vascular inflammation by inhibiting the inflammasome activation in vitamin D2treated rats with hypercholesterolemia. In the present study, the administration of resveratrol in rats reduced their vascular histopathological changes, von Willebrand factor levels, and serum IL-1 $\beta$ levels. It also lowered the expression levels of mRNA and the proteins of NLRP3 inflammasome, caspase-1, and apoptosis-associated speck-like a protein containing CARD (ASC) (13). A study had previously evaluated the effect of resveratrol modulation on the inflammatory responses caused by myocardial ischemia and reperfusion $(\mathrm{I} / \mathrm{R})$ in rats. By administrating resveratrol with different concentrations, the pathology and morphology had significantly improved. In addition, resveratrol had decreased both mRNA and protein levels of NLRP3 and CASP- 1 and had significantly modulated IL- $1 \beta$ and IL-18 activations as well (14). This compound has also protected the body against chronic intermittent hypoxia $(\mathrm{CIH})$-induced myocardial injury by targeting nuclear factor erythroid $2(\mathrm{NrF} 2)$ as well as blocking NLRP3 inflammasome activation. Moreover, $\mathrm{CIH}$-impaired cardiac structure and function along with the increased oxidative stress, endoplasmic reticulum (ER) stress, and NLRP3 induction in the heart had been evaluated. Accordingly, these effects had been attenuated following the administration of resveratrol (15). It was indicated that resveratrol could prevent cardiac injury induced by pulmonary embolism (PE), and reduce PEinduced cardiac injury by suppressing the inflammasome activation (16).

The effect of resveratrol on inflammasome in brain injuries

Resveratrol was found to reduce brain injury $I / R$ in rats by the inhibition of the NLRP3 inflammasome activation and the induction of SIRT1-dependent autophagy. Brain injury following $\mathrm{I} / \mathrm{R}$ could increase the activities of NLRP3 inflammasome, CASP-1, IL-1 $\beta$, and IL-18. Thereafter, in this study, the treatment with resveratrol had further minimized I/R injury by NLRP3 inflammasome activity and also increased autophagy. (17). Furthermore, it was demonstrated that resveratrol protects the brain against sepsis-associated encephalopathy (SAE), which is known as cerebral dysfunction associated with sepsis (18), and inhibits NLRP3/IL-1 $\beta$ axis in microglia. Correspondingly, the given compound can also inhibit early brain injury (EBI) after experimental subarachnoid hemorrhage (SAH) via the inhibition of the NLRP3 inflammasome activation. Moreover, resveratrol has some beneficial effects on traumatic brain injury (TBI) and SAH (18). In this regard, a study has investigated the neuroprotective 
effects of resveratrol and the basic mechanisms associated with the control effect of this compound, on NLRP3 inflammasome in TBI. It was also shown that resveratrol pre-treatment could prevent the activations of NLRP3 and CASP-1 and also reduce the productions of inflammatory cytokines and ROS. Ischemic injury increases the TXNIP expression in rats as well. On the other hand, resveratrol prevents TXNIP expression and protects the brain from ischemic injury (19).

The effect of resveratrol on inflammasome in kidney failure

Resveratrol-loaded nanoparticles (Res-NPs) conjugated with anti-kidney injury molecule (KIM-1) antibodies are exploited as a potential drug delivery system during chronic kidney disease (CKD). Therefore, the anti-KIM-1 antibodies have been linked to Res-NPs and then analyzed for their safety and efficacy. Res-NPs have a low toxicity, which also induces autophagy. Hence, they may also be considered as a solution to prevent CKD through the attenuation of NLRP3 inflammasome and the induction of autophagy (20). In this regard, the injection of resveratrol can reduce glomerular proliferation, glomerulosclerosis, and glomerulonephritis in a rat model of progressive immunoglobulin A ( $\operatorname{IgA}$ ) nephropathy. These findings are associated with the decreased renal mononuclear leukocyte infiltration, the lowered renal superoxide anion levels, and the inhibited renal NLRP3 inflammasome activation (21). Accordingly, a study had previously evaluated the protective effect of resveratrol on the rat model of contrastinduced nephropathy (CIN). In this study, the resveratrol treatment had further reduced both injury and apoptosis processes and also inhibited inflammasome pathway in the CIN rat model (22). As it was observed, resveratrol can inhibit TXNIP binding to NLRP3 in diabetic rats exposed to renal I/R injury. Under the conditions of hyperglycemia and exposure to hypoxia-reoxygenation (H/R) for one time, human kidney 2 (HK-2) cells can also lead to the stimulation of TXNIP expression with the increased NLRP3 expression, as well as the higher productions of ROS, CASP-1, and IL- $1 \beta$, and the exacerbation of HK-2 cell apoptosis. Correspondingly, all these changes can be moderated with resveratrol treatment (23).

The effect of resveratrol on inflammasome in liver failure

The liver is one of the organs that seems to be damaged by unbridled inflammation caused by SARS-CoV-2 (24). In a study, pro-inflammatory markers had been assessed in the liver of aged male rats and the effect of resveratrol on these inflammatory markers was then evaluated. As a result, resveratrol had reduced IL- $1 \beta$ and TNF- $\alpha$ levels in these aged rats. The mRNA levels of NALP-3, ASC, CASP1, COX-2, and NALP-1 had further displayed an agedependent increase that was reversed by resveratrol (25). Resveratrol also regulates NAD bioavailability and SIRT1- related metabolism, which are associated with aging, metabolic syndrome, and non-alcoholic fatty liver diseases. In another study, glucose control had been disrupted and subsequently, serum and liver triglyceride (TG) levels had augmented after four weeks of the treatment with resveratrol in high-fat-diet rat models. Thereafter, resveratrol injections had significantly improved glucose control as well as TG contents of the serum and the liver. These improvements had been accompanied by some changes in SIRT1 and NLRP3 pathways (26).

Other studies on the effect of resveratrol on inflammasome

Psoriasis is a chronic immune-mediated inflammatory disease of the skin. Although the activation of absent in melanoma 2 (AIM2) inflammasome is important for immune defense, it can lead to some inflammatory and autoimmune diseases like psoriasis. Consequently, the EFLA 945 containing resveratrol can limit the activation of AIM2 inflammasome. In a rat model, the EFLA'945 had reduced inflammatory responses caused by psoriasis, including CASP-1 activation, IL- $1 \beta$ secretion, and IL17 production (27). The IL-1 $\beta$ production following the NLRP3 activation due to the monocyte/macrophage treatment with monosodium urate (MSU) was also shown to be responsible for the pathogenesis of gouty arthritis. In a rat model, resveratrol had further reduced recurrent attacks of MSU-induced arthritis. The given compound had similarly suppressed IL- $1 \beta$ secretion by primary human monocytes stimulated with MSU crystals (28). In this regard, a previous study had investigated the potential impact of SIRT 1 on the radiation-induced IL- $1 \beta$ expression in mesenchymal stem cells (MSCs). Accordingly, radiation had significantly increased IL- $1 \beta$ mRNA and protein levels, and pre-treatment with resveratrol, as a SIRT1 activator, had also inhibited the radiation-induced IL-1 $\beta$ expression in a dose-dependent manner (29). Moreover, the effects of metformin and resveratrol on ROS production, mitochondrial fission, ER stress, TXNIP/ NLRP3 activation, inflammation, and apoptosis had been also investigated in high glucose-exposed adipose tissues. It was found that metformin and resveratrol could protect mitochondrial fission by the inhibition of the dynamin-like protein 1 activity as well as the prevention of the NLRP3 inflammasome activation (30). Resveratrol can also inhibit the accumulation of acetylated $\alpha$-tubulin due to causing mitochondrial damage in macrophages resulted from the NLRP3 activation, and prevent their subsequent exposures to ER, which can consequently lead to the insufficient accumulation of ASC in mitochondria and NLRP3 in ER (31). A study examined the role of pyrophosphate crystals and resveratrol in the inflammatory process produced by MSU and calcium pyrophosphate. As a result, cell treatment was effective on reducing IL- $1 \beta$ mRNA expression, while it had no effect on NLRP3 gene expression (32). Another study had further evaluated the 
effect of dialysis solutions containing high glucose on mitochondrial ROS and NLRP3 activations in human polymorphonuclear cells. In this regard, the exposure of polymorphonuclear cells to dialysis solutions led to ROS production, which could subsequently activate NLRP3 and then result in IL-1B secretion. It had also induced mitophagy/autophagy, and then the resveratrol treatment had weakened this effect (33). In intestinal ischemiareperfusion (IIR) injury, pre-treatment with resveratrol can reduce the activation of mast cells (MCs) and NLRP3 inflammasome. Consequently, it can suppress IIR injury by stabilizing $\mathrm{MC}$ and inhibiting their degranulation, as observed along with the inhibition of inflammatory bowel disease (IBD), the decreased NLRP3, and intestinal epithelial cell (EC) apoptosis (34). Table 1 shows different effects of resveratrol on different pathological conditions.

\section{Conclusion}

COVID-19 in comorbidity with multi-organ failure can cause disorders in various organs and systems of the body such as lungs, heart, liver, kidneys, blood circulation and neural network. Some of the extra-pulmonary presentations caused by COVID-19 infection include blood agglutination, loss of smell and taste, conjunctivitis, hepatic failure, acute renal failure, rashes and acute encephalitis, which are attributed to SARS-CoV-2. There are multiple causes for death from COVID-19, the most important of which is spread of infection to different organs such as RBC (thromboembolism), immune cell, gastrointestinal tract, endothelium, brain, kidney, liver and heart via the angiotensin converting enzyme 2 receptor, depending on the viral load. The present study was conducted to fight against the inflammation by impeding the inflammasomes

Table 1. Direct/indirect effects of resveratrol on inflammation and various other diseases

\begin{tabular}{|c|c|c|c|c|}
\hline Diseases & Model & Outcome & Mechanisms & Ref \\
\hline Traumatic brain injury & Rat & $\begin{array}{l}\text { TBI and inflammatory response might be reduced by } \\
\text { RSV through an inhibition in NLRP3 activation and a } \\
\text { decrease in ROS formation }\end{array}$ & $\begin{array}{l}\text { SIRT1-dependent manner may be suggested in } \\
\text { the RSV impact on ROS formation and NLRP3 } \\
\text { inflammasome }\end{array}$ & (35) \\
\hline $\begin{array}{l}\text { Intestinal ischemia- } \\
\text { reperfusion }\end{array}$ & Rat & IIR injury was improved by RSV & $\begin{array}{l}\text { Prevention of mast cell degranulation and their } \\
\text { stabilization, resulting in the inhibition of NLRP3 } \\
\text { inflammasome and induction of apoptosis }\end{array}$ & (34) \\
\hline Early brain injury & Rat & EBI could be controlled by RSV & An inhibition in NLRP3 inflammasome signaling & (18) \\
\hline $\begin{array}{l}\text { Hepatic } \\
\text { metaflammation }\end{array}$ & $\begin{array}{l}\text { Male } \\
\text { C57BL/6 J }\end{array}$ & Pro-inflammatory markers were decreased by RSV & $\begin{array}{l}\text { A change in the activation of NLRP3 } \\
\text { inflammasome and SIRT1 pathway }\end{array}$ & (26) \\
\hline $\begin{array}{l}\text { Ischemic acute kidney } \\
\text { injury in diabetes }\end{array}$ & $\begin{array}{l}\text { Rat } \\
\text { HK-2 cells }\end{array}$ & $\begin{array}{l}\text { The formation of IL-18 and IL- } 1 \beta \text { and the expression } \\
\text { level of cleaved caspase- } 1 \text { were dropped and TXNIP- } \\
\text { NLRP3 binding was inhibited significantly following the } \\
\text { administration of RSV }\end{array}$ & $\begin{array}{l}\text { The activation of NLRP3 mediated by TXNIP via } \\
\text { oxidative stress }\end{array}$ & $(23)$ \\
\hline $\begin{array}{l}\text { Pneumonia } \\
\text { Staphylococcus aureus }\end{array}$ & $\begin{array}{l}\text { Murine } \\
\text { model }\end{array}$ & $\begin{array}{l}\text { The risk of pneumonia caused by S. aureus in mice was } \\
\text { reduced significantly by RSV }\end{array}$ & The NLRP3 inflammasome inhibition & (11) \\
\hline $\begin{array}{l}\text { Peritoneal } \\
\text { inflammatory injury }\end{array}$ & $\begin{array}{l}\text { Peritoneal } \\
\text { mesothelial } \\
\text { cells }\end{array}$ & $\begin{array}{l}\text { Autophagy/mitophagy was induced by RSV through the } \\
\text { activation of AMPK signaling pathway }\end{array}$ & $\begin{array}{l}\text { The activation of NLRP3 inflammasome via } \\
\text { mitochondrial ROS }\end{array}$ & (33) \\
\hline Liver & $\begin{array}{l}\text { Old male } \\
\text { C57BL/6J }\end{array}$ & $\begin{array}{l}\text { The meta-inflammation in the liver was attenuated by } \\
\text { RSV in old mice }\end{array}$ & $\begin{array}{l}\text { Reversing the COX-2 and NALP-3 inflammasome } \\
\text { components }\end{array}$ & $(25)$ \\
\hline $\begin{array}{l}\text { Chronic intermittent } \\
\text { hypoxia }\end{array}$ & Rat & $\begin{array}{l}\text { RSV can inhibit mTNA/TTP/ NLRP3 mRNA signaling by } \\
\text { activating AMPK. }\end{array}$ & $\begin{array}{l}\text { Impeding the activation of NLRP3 inflammasome } \\
\text { and targeting Nrf2 }\end{array}$ & (15) \\
\hline $\begin{array}{l}\text { Sepsis-associated } \\
\text { encephalopathy }\end{array}$ & $\begin{array}{l}\text { Mice BV2 } \\
\text { cell lines }\end{array}$ & $\begin{array}{l}\text { The spatial memory recovery by RSV in SAE-induced } \\
\text { mice }\end{array}$ & Blocking NLRP3/IL-1 $\beta$ axis present in microglia & (36) \\
\hline Monocytic cell line & THP-1 & $\begin{array}{l}\text { The crystal-induced inflammation was impeded by PD } \\
\text { and RSV }\end{array}$ & $\begin{array}{l}\text { The inhibition of } \mathrm{NO} \text { and } \mathrm{ROS} \text { formation and the } \\
\text { reduction of IL-1 mRNA expression }\end{array}$ & $(32)$ \\
\hline Spinal cord injury & $\begin{array}{l}\text { Rats } \\
\text { BV2 } \\
\text { microglia }\end{array}$ & $\begin{array}{l}\text { Neuroprotective potential was observed for polydatin in } \\
\text { the induced } \mathrm{SCl} \text { rats }\end{array}$ & $\begin{array}{l}\text { Blocking the production of iNOS and the } \\
\text { activation of NLRP3 inflammasome in the } \\
\text { microglia }\end{array}$ & $(37)$ \\
\hline CKD & $\begin{array}{l}\text { Murine } \\
\text { model }\end{array}$ & CKD might be controlled by RSV-loaded NPs & $\begin{array}{l}\text { Reduction of NLRP3 inflammasome and } \\
\text { induction of autophagy }\end{array}$ & (20) \\
\hline Toxicity of nickel & BEAS-2B & $\begin{array}{l}\text { Ni-induced cytotoxicity on BEAS-2B cells can be } \\
\text { prevented by RSV }\end{array}$ & $\begin{array}{l}\text { The inhibition of NLRP3 inflammasome } \\
\text { activation and NF-kB and p38 MAPK signaling }\end{array}$ & (9) \\
\hline $\begin{array}{l}\text { Progressive IgA } \\
\text { nephropathy }\end{array}$ & $\begin{array}{l}\text { Mouse, } \\
\text { J774A.1 }\end{array}$ & NLRP3 inflammasome was inactivated by RSV & $\begin{array}{l}\text { The establishment of mitochondrial integrity and } \\
\text { by the enhancement of autophagy }\end{array}$ & (21) \\
\hline
\end{tabular}


Table 1. Continued

\begin{tabular}{|c|c|c|c|c|}
\hline Diseases & Model & Outcome & Mechanisms & Ref \\
\hline $\begin{array}{l}\text { Contrast-induced } \\
\text { nephropathy }\end{array}$ & Rat model & Apoptosis and injury processes were reduced by RSV & $\begin{array}{l}\text { Blocking inflammasome activation in rat model } \\
\text { of } \mathrm{CIN}\end{array}$ & $(22)$ \\
\hline Nephrotoxicity & HK-2 cells & $\begin{array}{l}\text { The Cd-mediated activation of NRLP3 inflammasome } \\
\text { and its pyroptosis and the IRE-1alpha/XBP-1s pathway } \\
\text { was inhibited }\end{array}$ & $\begin{array}{l}\text { The mediation of deacetylating XBP-1s to } \\
\text { preserve SIRT1 activity versus pyroptosis induced } \\
\text { by } \mathrm{Cd}\end{array}$ & $(38)$ \\
\hline Gouty arthritis & $\begin{array}{l}\text { Murine } \\
\text { model }\end{array}$ & MSU-induced peritonitis was improved by RSV in mice & $\begin{array}{l}\text { The mediation of } \mathrm{p} 38 \text { and Syk to influence } \\
\text { adversely pro-IL-1 } \beta \text { formation, as well as the } \\
\text { inhibition of ASC oligomerization. }\end{array}$ & $(28)$ \\
\hline Vascular injury & Rat & $\begin{array}{l}\text { A therapeutic activity was found for RSV against the } \\
\text { vascular injury }\end{array}$ & Impeding the activation of inflammasome & (13) \\
\hline $\begin{array}{l}\text { Lung inflammation } \\
\text { and fibrosis }\end{array}$ & $\begin{array}{l}\mathrm{C} 57 \mathrm{BL} / 6 \mathrm{~J} \\
\text { mice BEAS- } \\
2 \mathrm{~B} \text { cells }\end{array}$ & $\begin{array}{l}\text { Fibrosis and inflammation of lung were improved by } \\
\text { RSV. }\end{array}$ & $\begin{array}{l}\text { Impeding the activation of NLRP3 inflammasome } \\
\text { related to autophagy }\end{array}$ & $(10)$ \\
\hline $\begin{array}{l}\text { Myocardial ischemia/ } \\
\text { reperfusion }\end{array}$ & Rat & $\begin{array}{l}\text { RSV exhibited cardio-protective activity to reduce the } \\
\text { inflammation }\end{array}$ & Impeding the NLRP-3 inflammasome activation & $(14)$ \\
\hline Radiation injury & MSCs & $\begin{array}{l}\text { The inflammation induced by ionizing irradiation was } \\
\text { impeded by RSV in MSCs. }\end{array}$ & $\begin{array}{l}\text { The induction of SIRT1 and the restriction of } \\
\text { NLRP-3 inflammasome }\end{array}$ & $(29)$ \\
\hline $\begin{array}{l}\text { Cerebral ischemia/ } \\
\text { reperfusion }(I / R)\end{array}$ & Rat & Cerebral I/R damage was improved by RSV & $\begin{array}{l}\text { The activity of SIRT1-dependent autophagy } \\
\text { caused an inhibition in NLRP3 inflammasome } \\
\text { activation }\end{array}$ & $(17)$ \\
\hline $\begin{array}{l}\text { Human acute } \\
\text { monocytic leukemia }\end{array}$ & THP-1 cells & $\begin{array}{l}\text { Anti-inflammatory potentials were seen for cis-RSV, } \\
\text { in accompanied with related pathways in human } \\
\text { macrophages }\end{array}$ & $\begin{array}{l}\text { The inhibition of non-canonical and canonical } \\
\text { inflammasomes }\end{array}$ & (39) \\
\hline Acute lung injury & Mice & Lung injury induced by LPS was inhibited by RSV & Prevention of NLRP3 inflammasome & $(12)$ \\
\hline
\end{tabular}

observed in different disorders, such as pulmonary edema, fibrosis, pneumonia, cardiac damage, chronic intermittent hypoxia, myocardial ischemia and reperfusion, TBI, SAH, EBI, SAE, CIN, CKD, IBD, IIR, psoriasis and liver failure. Findings can be useful in the COVID-19 epidemic to reach several effective food supplements, anti-coronavirus treatments and therapeutic adjuncts. Moreover, we found that resveratrol can influence and inhibit the hyper-activation of diverse inflammasome regulators, such as ASC, p38, Syk, Nrf2, TXNIP and SIRT1. The resveratrol can employ various pathways, in particular the inhibition of NLRP3 inflammasome, to improve the conditions, such as inhibited ionizing irradiation, fibrosis, abolished lung inflammation, spatial memory, metainflammation, pneumonia, lung inflammation, sepsisrelated encephalopathy, IBD, IIR and psoriasis. It can be claimed that resveratrol is a promising candidate to manage the severe form of COVID-19 infection. However, there is further need for clinical trials to reach a definitive conclusion in this area. Given the persistence of the COVID-19 pandemic and the challenges of widespread vaccination in all countries, it is essential to achieve more effective treatments to reduce the mortality rate and severity of severe injuries following COVID-19. Given all the effects reviewed in this article, resveratrol at a dose of up to $600 \mathrm{mg}$ per day can be exploited as a potential adjunctive therapy for COVID-19 patients.

\section{Authors' contribution}

$A A, A S B$ and MMS were the principal investigators of the study. $\mathrm{SHH}, \mathrm{AKH}, \mathrm{STG}$ and MMS were included in preparing the concept and design. MMS, ASB and AA revised the manuscript and critically evaluated the intellectual contents. All authors participated in preparing the final draft of the manuscript, revised the manuscript and critically evaluated the intellectual contents. Authors have read and approved the content of the manuscript and confirmed the accuracy or integrity of any part of the work.

\section{Conflicts of interest}

The authors declare that they have no competing interests.

\section{Ethical issues}

Ethical issues (including plagiarism, data fabrication, double publication) have been completely observed by the authors. This article does not contain any studies with human participants or animals performed by any of the authors.

\section{Funding/Support}

This study was supported by grants from vice chancellor for research affairs, Ahvaz Jundishapur University of Medical Sciences, Ahvaz, Iran.

References

1. Diaz M, Avila A, Degens H, Coeckelberghs E, 
Vanhees L, Cornelissen $\mathrm{V}$, et al. Acute resveratrol supplementation in coronary artery disease: towards patient stratification. Scand Cardiovasc J. 2020;54:14-19. doi: 10.1080/14017431.2019.1657584.

2. Dong S, Sun J, Mao Z, Wang L, Lu YL, Li J. A guideline for homology modeling of the proteins from newly discovered betacoronavirus, 2019 novel coronavirus (2019-nCoV). J Med Virol. 2020;92:1542-8. doi: 10.1002/jmv.25768.

3. Lekli I, Ray D, Das DK. Longevity nutrients resveratrol, wines and grapes. Genes Nutr. 2010;5:55-60. doi: 10.1007/s12263009-0145-2.

4. Berman AY, Motechin RA, Wiesenfeld MY, Holz MK. The therapeutic potential of resveratrol: a review of clinical trials. NPJ Precis Oncol. 2017;1:35. doi: 10.1038/s41698-017-00386.

5. Wiciński M, Socha M, Walczak M, Wódkiewicz E, Malinowski B, Rewerski S, et al. Beneficial Effects of Resveratrol Administration-Focus on Potential Biochemical Mechanisms in Cardiovascular Conditions. Nutrients. 2018;10:1813. doi: 10.3390/nu10111813.

6. de Sá Coutinho D, Pacheco MT, Frozza RL, Bernardi A. Antiinflammatory effects of resveratrol: Mechanistic insights. Int J Mol Sci. 2018;19:1812. doi: 10.3390/ijms19061812.

7. Öztürk E, Arslan AKK, Yerer MB, Bishayee A. Resveratrol and diabetes: A critical review of clinical studies. Biomed Pharmacother. 2017;95:230-234. doi: 10.1016/j. biopha.2017.08.070.

8. Zhu X-d, Lei X-p, Dong W-b. Resveratrol as a potential therapeutic drug for respiratory system diseases. Drug Des Devel Ther. 2017;11:3591-8. doi: 10.2147/DDDT.S148868.

9. Cao X, Tian S, Fu M, Li Y, Sun Y, Liu J, et al. Resveratrol protects human bronchial epithelial cells against nickel-induced toxicity via suppressing p38 MAPK, NF-kappaB signaling, and NLRP3 inflammasome activation. Environ Toxicol. 2020;35:609-18. doi: 10.1002/tox.22896

10. Ding $\mathrm{S}$, Wang $\mathrm{H}$, Wang $\mathrm{M}$, Bai L, Yu $\mathrm{P}, \mathrm{Wu}$ W. Resveratrol alleviates chronic "real-world" ambient particulate matterinduced lung inflammation and fibrosis by inhibiting NLRP3 inflammasome activation in mice. Ecotoxicol Environ Saf. 2019;182:109425. doi: 10.1016/j.ecoenv.2019.109425.

11. Wu S, Huang J. Resveratrol alleviates Staphylococcus aureus pneumonia by inhibition of the NLRP3 inflammasome. Exp Ther Med. 2017;14:6099-104. doi: 10.3892/etm.2017.5337.

12. Jiang L, Zhang L, Kang K, Fei D, Gong R, Cao Y, et al. Resveratrol ameliorates LPS-induced acute lung injury via NLRP3 inflammasome modulation. Biomed Pharmacother. 2016;84:130-8. doi: 10.1016/j.biopha.2016.09.020.

13. Deng ZY, Hu MM, Xin YF, Gang C. Resveratrol alleviates vascular inflammatory injury by inhibiting inflammasome activation in rats with hypercholesterolemia and vitamin D2 treatment. Inflamm Res. 2015;64:321-32. doi: 10.1007/ s00011-015-0810-4

14. Dong W, Yang R, Yang J, Yang J, Ding J, Wu H, et al. Resveratrol pretreatment protects rat hearts from ischemia/reperfusion injury partly via a NALP3 inflammasome pathway. Int J Clin Exp Pathol. 2015;8:8731-41

15. Sun ZM, Guan P, Luo LF, Qin LY, Wang N, Zhao YS, et al. Resveratrol protects against $\mathrm{CIH}$-induced myocardial injury by targeting Nrf2 and blocking NLRP3 inflammasome activation. Life Sci. 2020;245:117362. doi: 10.1016/j.Ifs.2020.117362.

16. Yang K, Li W, Duan W, Jiang Y, Huang N, Li Y, et al. Resveratrol attenuates pulmonary embolism associated cardiac injury by suppressing activation of the inflammasome via the MALAT1miR223p signaling pathway. Int J Mol Med. 2019;44:2311-2320. doi: 10.3892/ijmm.2019.4358.

17. He Q, Li Z, Wang Y, Hou Y, Li L, Zhao J. Resveratrol alleviates cerebral ischemia/reperfusion injury in rats by inhibiting NLRP3 inflammasome activation through Sirt1-dependent autophagy induction. Int Immunopharmacol. 2017;50:20815. doi: 10.1016/j.intimp.2017.06.029.

18. Zhang X, Wu Q, Zhang Q, Lu Y, Liu J, Li W, et al. Resveratrol Attenuates Early Brain Injury after Experimental Subarachnoid Hemorrhage via Inhibition of NLRP3 Inflammasome Activation. Front Neurosci. 2017;11:611. doi: 10.3389/fnins.2017.00611.

19. Ishrat T, Mohamed IN, Pillai B, Soliman S, Fouda AY, Ergul A, et al. Thioredoxin-interacting protein: a novel target for neuroprotection in experimental thromboembolic stroke in mice. Mol Neurobiol. 2015;51:766-78. doi: 10.1007/s12035014-8766-X.

20. Lin YF, Lee $Y H$, Hsu YH, Chen YJ, Lin YF, Cheng FY, et al. Resveratrol-loaded nanoparticles conjugated with kidney injury molecule-1 as a drug delivery system for potential use in chronic kidney disease. Nanomedicine (Lond). 2017;12:274156. doi: 10.2217/nnm-2017-0256.

21. Chang YP, Ka SM, Hsu WH, Chen A, Chao LK, Lin CC, et al. Resveratrol inhibits NLRP3 inflammasome activation by preserving mitochondrial integrity and augmenting autophagy. J Cell Physiol. 2015;230:1567-79. doi: 10.1002/jcp.24903.

22. Chen YH, Fu YC, Wu MJ. Does Resveratrol Play a Role in Decreasing the Inflammation Associated with Contrast Induced Nephropathy in Rat Model? J Clin Med. 2019;8:147. doi: 10.3390/jcm8020147.

23. Xiao YD, Huang $Y Y$, Wang $H X$, Wu Y, Leng $Y$, Liu M, et al. Thioredoxin-Interacting Protein Mediates NLRP3 Inflammasome Activation Involved in the Susceptibility to Ischemic Acute Kidney Injury in Diabetes. Oxid Med Cell Longev. 2016;2016:2386068. doi: 10.1155/2016/2386068.

24. Rismanbaf A, Zarei S. Liver and kidney injuries in COVID-19 and their effects on drug therapy; a letter to editor. Arch Acad Emerg Med. 2020;8:e17.

25. Tung BT, Rodriguez-Bies E, Talero E, Gamero-Estevez E, Motilva $\mathrm{V}$, Navas $\mathrm{P}$, et al. Anti-inflammatory effect of resveratrol in old mice liver. Exp Gerontol. 2015;64:1-7. doi: 10.1016/j.exger.

26. Yang SJ, Lim Y. Resveratrol ameliorates hepatic metaflammation and inhibits NLRP3 inflammasome activation. Metabolism. 2014;63:693-701. doi: 10.1016/j.metabol.2014.02.003.

27. Chung IC, Yuan SN, OuYang CN, Hu SI, Lin HC, Huang $\mathrm{KY}$, et al. EFLA 945 restricts AIM2 inflammasome activation by preventing DNA entry for psoriasis treatment. Cytokine. 2020;127:154951. doi: 10.1016/j.cyto.2019.154951.

28. Chung YH, Kim HY, Yoon BR, Kang YJ, Lee WW. Suppression of Syk activation by resveratrol inhibits MSU crystal-induced inflammation in human monocytes. J Mol Med (Berl). 2019;97:369-383. doi: 10.1007/s00109-018-01736-y.

29. Fu Y, Wang Y, Du L, Xu C, Cao J, Fan T, et al. Resveratrol inhibits ionising irradiation-induced inflammation in MSCs by activating SIRT1 and limiting NLRP-3 inflammasome activation. Int J Mol Sci. 2013;14:14105-18. doi: 10.3390/ ijms140714105.

30. Li A, Zhang S, Li J, Liu K, Huang F, Liu B. Metformin and resveratrol inhibit Drp1-mediated mitochondrial fission and prevent ER stress-associated NLRP3 inflammasome activation in the adipose tissue of diabetic mice. Mol Cell Endocrinol. 2016;434:36-47. doi: 10.1016/j.mce.2016.06.008.

31. Misawa T, Saitoh T, Kozaki T, Park S, Takahama M, Akira S. Resveratrol inhibits the acetylated alpha-tubulin-mediated assembly of the NLRP3-inflammasome. Int Immunol. 2015;27:425-34. doi: 10.1093/intimm/dxv018.

32. Oliviero F, Zamudio-Cuevas $\mathrm{Y}$, Belluzzi E, Andretto L, Scanu $A$, Favero $M$, et al. Polydatin and resveratrol inhibit the inflammatory process induced by urate and pyrophosphate crystals in THP-1 cells. Foods. 2019;8:560. doi: 10.3390/ 
foods8110560.

33. WuJ, Li X, Zhu G, ZhangY, HeM, Zhang J. The role of Resveratrolinduced mitophagy/autophagy in peritoneal mesothelial cells inflammatory injury via NLRP3 inflammasome activation triggered by mitochondrial ROS. Exp Cell Res. 2016;341:4253. doi: 10.1016/j.yexcr.2016.01.014.

34. Zhao W, Huang X, Han X, Hu D, Hu X, Li Y, et al. Resveratrol Suppresses Gut-Derived NLRP3 inflammasome partly through stabilizing mast cells in a rat model. Mediators Inflamm. 2018;2018:6158671. doi: 10.1155/2018/6158671.

35. Zou P, Liu X, Li G, Wang Y. Resveratrol pretreatment attenuates traumatic brain injury in rats by suppressing NLRP3 inflammasome activation via SIRT1. Mol Med Rep. 2018;17:3212-3217. doi: 10.3892/mmr.2017.8241.

36. Sui DM, Xie Q, Yi WJ, Gupta S, Yu XY, Li JB, et al. Resveratrol Protects against Sepsis-Associated Encephalopathy and Inhibits the NLRP3/IL-1 beta Axis in Microglia. Mediators Inflamm.
2016;2016:1045657. doi: 10.1155/2016/1045657.

37. Lv R, Du L, Liu X, Zhou F, Zhang Z, Zhang L. Polydatin alleviates traumatic spinal cord injury by reducing microglial inflammation via regulation of iNOS and NLRP3 inflammasome pathway. Int Immunopharmacol. 2019;70:2836. doi: 10.1016/j.intimp.2019.02.006.

38. Chou X, Ding F, Zhang X, Ding X, Gao H, Wu Q. Sirtuin-1 ameliorates cadmium-induced endoplasmic reticulum stress and pyroptosis through XBP-1s deacetylation in human renal tubular epithelial cells. Arch Toxicol. 2019;93:965-986. doi: 10.1007/s00204-019-02415-8.

39. Huang TT, Lai HC, Chen YB, Chen LG, Wu YH, Ko YF, et al. cis-Resveratrol produces anti-inflammatory effects by inhibiting canonical and non-canonical inflammasomes in macrophages. Innate Immun. 2014;20:735-50. doi: 10.1177/1753425913507096. 